
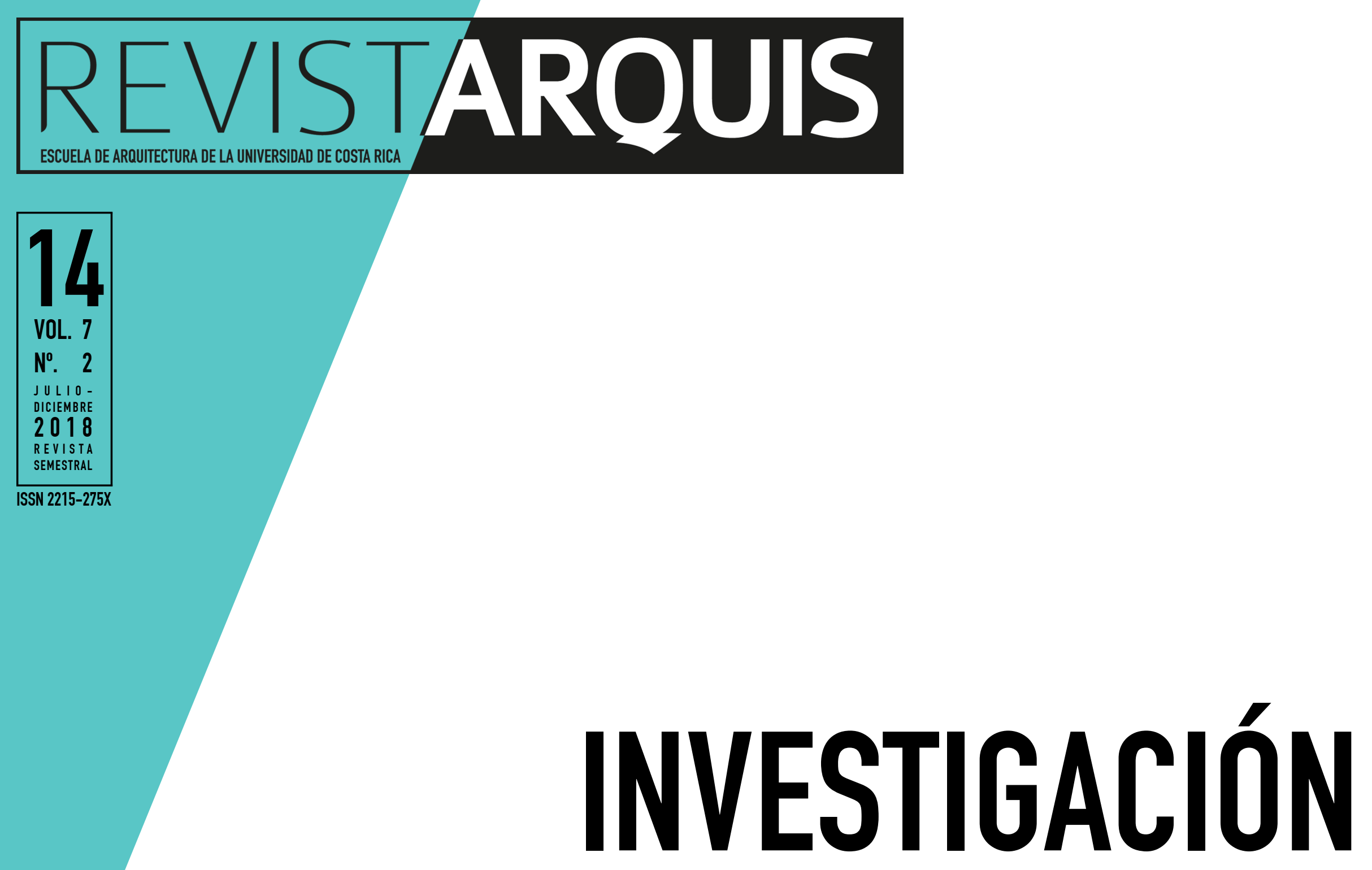

RESEARCH

\author{
Propuesta de vivienda incremental para la comunidad tsáchila a través métodos \\ participativos \\ Daniela Hidalgo Molina, Juan Diego Ponce y Gisella Raymond Cornejo. | 1-16 \\ Injusticia espacial urbana en asentamientos informales \\ Milena Rincón Castellanos | 17-29
}




\title{
Propuesta de vivienda incremental para la comunidad tsáchila a través métodos participativos
}

\author{
Daniela Hidalgo Molina, Juan Diego Ponce y Gisella Raymond \\ Cornejo.
}

Investigación

Invitados internacionales

Ecuador

Institución: Universidad Espíritu Santo-Ecuador,

Facultad de Arquitectura

Institución: Universidad Laica Vicente Rocafuerte, Facultad de Ciencias Sociales y Derecho.

E-mail: mdhidalgo@uees.edu.ec

E-mail: jdiegoponcee@gmail.com

E-mail: giselraymond@gmail.com

Recibido: 20 de febrero del 2018

Aceptado: 4 de mayo del 2018

\section{María Daniela Hidalgo Molina}

Arquitecta, PhD. Profesora Investigadora, Universidad Espíritu Santo-Ecuador, Facultad de Arquitectura.

\section{Juan Diego Ponce \\ Arquitecto e investigador independiente.}

\section{Gisela Raymond Cornejo}

Licenciada y Máster, Universidad Laica Vicente Rocafuerte, Facultad de Ciencias Sociales y Derecho.

Con la colaboración de:

Ministerio de Desarrollo Urbano y Vivienda (MIDUVI) de Santo Domingo de los Tsáchilas. Director Arq. Jonathan Carpio; Arq. María Luisa Ortega.

\begin{abstract}
Resumen:
La vivienda es una expresión cultural, pues representa cómo los habitantes se relacionan con el territorio. Ecuador es un país multicultural donde la diversidad se manifiesta a través de los distintos hábitats. Los Tsáchilas, también llamados Colorados, habitan en Santo Domingo de los Tsáchilas y, por sus costumbres y tradiciones, los integrantes de esta etnia esperan ser declarados Patrimonio de la Humanidad por la Unesco. Deacuerdo con el último censo habitacional, Santo Domingo de los Tsáchilas es el segundo sector del país con déficit habitacional. Después del terremoto del 16 de abril del 2016, varias viviendas de las comunidades Tsáchilas fueron afectadas. Estas serán reemplazadas por una vivienda nueva por lo que la academia aporta el diseño de un prototipo de vivienda social con criterios formales y funcionales de la etnia tsáchila. Durante las visitas en el sitio se realizaron levantamientos de vivienda, entrevistas y talleres para determinar criterios arquitectónicos. Utilizando la caña guadua como principal material, se realizó esta nueva propuesta que continua en proceso de socialización, esperando ser una opción de vivienda incremental para el catálogo del Ministerio de Desarrollo Urbano y Vivienda.
\end{abstract}

Palabras clave: comunidad tsáchila; diseño participativo; vivienda incremental; vivienda vernácula.

Incremental housing proposal for the tsáchila community through participatory methods

\begin{abstract}
:
Housing is a cultural expression because it represents how the inhabitants relate to their territory. Ecuador is a multicultural country where diversity manifests itself in different habitats. The Tsáchilas, also called Colorados, live in Santo Domingo de Los Tsáchilas. Due to their customs and traditions, the members of this ethnic group hope to be declared a World Heritage Site by Unesco. According to the last housing census, Santo Domingo de Los Tsáchilas is the second sector of the country with a housing deficit. After the earthquake on April 16, 2016, around 70 families in the Tsáchilas communities had their homes affected which is why the academy contributes in designing a social housing prototype with formal and functional criteria of the Tsáchila ethnic group. Many housing surveys, interviews and workshops were made to determine the architectural criteria. The new proposal uses bamboo as the main material which continues in the process of socialization, hoping to be an incremental housing option for the catalog of the Ministry of Urban Development and Housing.
\end{abstract}

Keywords: Tsáchila's community; participatory design; incremental housing; vernacular housing. 


\section{Introducción}

no de los objetivos de la segunda Conferencia de las Naciones Unidas sobre los Asentamientos Humanos establece que las personas dispongan de una vivienda adecuada, mediante un criterio que favorezca el desarrollo y la mejora de la vivienda sin perjudicar al medio ambiente (Naciones Unidas, 1996). Siguiendo este lineamiento en la Conferencia de las Naciones Unidas Hábitat III, se estipula el tener diversas opciones de vivienda adecuada considerando la integración socioeconómica y cultural de las comunidades marginadas (Naciones Unidas, 2016).

Por su parte, la Constitución ecuatoriana del 2008 plantea como un derecho el acceso a una vivienda adecuada y digna (Constitución de la República del Ecuador, 2008). Asimismo, el Plan de Desarrollo Participativo 2002-2012 de las nacionalidades Tsáchilas incentiva la construcción de viviendas con material de la zona por medio de participación comunitaria con la finalidad de disminuir el déficit de vivienda en las zonas rurales (Consejo de Gobierno Tsáchila, 2002-2012). Es por esto que se presenta al Ministerio de Desarrollo Urbano y Vivienda (MIDUVI) una alternativa de vivienda social, considerando criterios formales y funcionales de los Tsáchilas para personas que carecen de vivienda.

Uno de los objetivos específicos del Plan del Buen Vivir o Seke Sónano (Tsáfiki) es la recuperación del ambiente, generando conocimiento cultural con propuestas de turismo comunitario sostenible. Para alcanzar este objetivo, la vivienda sustentable es necesaria para reflejar la identidad de los pueblos ya que es parte del contexto físico (Gobernación de la Nacionalidad Tsáchila Plan de Vida, 2017).

En el Ecuador existen 2'828.360 viviendas, el déficit de vivienda en "Santo Domingo de los Tsáchilas es de 350.967 y tiene 36.867 hogares precarios, representa el $47 \%$ del total de los hogares, siendo el segundo sector del país con déficit habitacional" (Ministerio de Desarrollo Urbano y Vivienda, 2015). Este porcentaje aumentó, sobre todo en la calidad de vivienda, a partir del terremoto del 16 de abril del 2016 que afectó a las estructuras de las viviendas en las comunidades tsáchilas.

Frente a esta situación, nace la propuesta de investigar la vivienda de esta zona costera del país para brindar una alternativa de solución habitacional adaptada al medio y apoyada en la comunidad. Además, la propuesta busca ser parte del catálogo de vivienda social para el ministerio.

Para lograrlo se han tomado las siguientes directrices:

1. Se han establecido criterios de diseño como línea base de la propuesta prototipo de vivienda tsáchila. Esta debe ajustarse al presupuesto sugerido por el Ministerio de Desarrollo y Vivienda (MIDUVI), de $\$ 12.500$ hasta $\$ 16.250$ dólares americanos + IVA y debe representar la identidad de la nacionalidad (Ministerio de Desarrollo Urbano y Vivienda, 2018).

2. El Plan del Buen Vivir tiene como visión buscar en el 2026 el fortalecimiento de su identidad y cosmovisión para que todas las familias tsáchilas cuenten con una vivienda propia que refleje su identidad utilizando tecnologías modernas y servicios básicos para garantizar el Seke Sónano (buen vivir) (Gobernación de la Nacionalidad Tsáchila Plan de Vida, 2017).

3. Las técnicas ancestrales requieren ser sustentables, por ello es imprescindible la utilización de materiales encontrados en el hábitat. La forma de la vivienda vernácula debe responder a los factores del clima. 


\section{Objetivo principal}

Diseñar un prototipo de vivienda social con criterios formales y funcionales de la etnia tsáchila por medio de métodos participativos para el catálogo de viviendas del MIDUVI.

\section{Objetivos específicos}

a) Identificar características formales y funcionales de la vivienda tsáchila por medio de levantamiento de viviendas en una comunidad determinada y talleres participativos.

b) Establecer criterios de la vivienda tsáchila.

c) Diseñar la vivienda con materiales de la zona, tales como la caña guadua.

La metodología de estudio es cualitativa, por medio de las siguientes técnicas de investigación: visita in situ, entrevistas, fotografías, levantamiento de viviendas para conocer la situación actual de la vivienda, recopilación de mapas de ubicación e información. Se realizó la visita de tres comunidades Tsáchilas: El Poste, Chiguilpe y El Bua para arrancar con el estudio de la vivienda. Adicionalmente, se organizaron los primeros tres talleres en la comunidad El Bua principalmente por la proximidad con el colegio Abraham Calazacón y el acceso con los líderes de la comunidad. El cuarto y quinto taller fueron realizados durante el foro público "Diálogo sobre la nueva Agenda Urbano Nacional-Socialización prototipo de vivienda tsáchila", donde participaron líderes y representantes de las siete comunidades. Cabe recalcar que el diseño de la vivienda continúa en proceso de socialización. Según datos de la oficina técnica del MIDUVI Santo Domingo, el proyecto está dirigido a las viviendas afectadas por el terremoto del 16 de abril de 2016 que afectó a siete comunidades Tsáchilas. El diseño de la vivienda busca ser parte del catálogo de viviendas del Ministerio, de quien dependerá la selección de las familias.

1. Primer taller: Vivienda y sus espacios.

2. Segundo taller: Problemas y soluciones de tú vivienda.

3. Tercer taller: Aprendiendo a realizar la cubierta de paja toquilla.

4. Cuarto taller: Alternativas en configuraciones de espacios.

5. Quinto taller: Calificación del anteproyecto. ${ }^{2}$

\section{Marco Teórico}

El estudio ayuda a determinar las características de la vivienda tsáchila, para realizar una propuesta de vivienda incremental considerando la integración socioeconómica y cultural, objetivo mencionado en Habitat III. El estudio de la vivienda vernácula, las situaciones de la vivienda actual y el involucramiento a las comunidades, ayuda a establecer patrones formales y funcionales del espacio. Los patrones como los define Cristhopher Alexander pueden ser diseñados y construidos, por un individuo o grupos de individuos (Alexander, 1977).

La vivienda tradicional o vernácula se refiere a las formas de construcción que pueden encontrarse en la zona rural como producto de una cultura que responde al entorno que le rodea con propuestas que se adaptan al medio ambiente (González, 2007). Esta vivienda representa múltiples experiencias acumuladas y transmitidas de generación en generación, y construida con ayuda de familiares, amigos y vecinos.

Gabriel Arboleda (como se cita en Cárdenas, 2014, p.15) describe a la arquitectura vernácula como "aquellas estructuras hechas por constructores empíricos de una manera informal" usando metodologías de diseño y materiales disponibles de la zona adecuadas al clima, topografía y forma de vida. Las estructuras, las formas y los materiales de construcción están determinados por el clima, geología, geografía, economía y la cultura local (Solis, 2014). Es necesario que durante el estudio se analice las viviendas vernáculas para determinar características generales que ayuden a establecer criterios arquitectónicos. 
ParaAlejandro Aravena (como se cita en Ornelas \&Amado, 2014) necesario salvaguardar la vivienda y adaptar su funcionamiento a las necesidades reales permitiendo así el crecimiento, esto se denomina la vivienda incremental. Por ejemplo, durante el estudio de la vivienda tsáchila, se observó las adiciones de cocina de leña y áreas sociales, de madera y caña a la vivienda de concreto. Estas adiciones responden a necesidades básicas del ser humano: comer y socializar.

La vivienda incremental es un concepto que el arquitecto Alejandro Aravena ha implementado en propuestas de vivienda social en Chile. Este concepto de vivienda incremental ya ha sido probado en proyectos como en la comunidad de Aranya. Esto indica que desde 1970 ha sido una propuesta de vivienda social (Ornelas \& Amado, 2014).

Además, en el proceso de generar propuestas es necesario la observación del comportamiento de las personas en el espacio físico; en este caso el comportamiento de las personas en la vivienda (Hester R. T., 1990). Para esto es necesario documentar las actividades realizadas durante el día (Gehl \& Svarre, 2013). Esto facilita al arquitecto el diseñar conforme a criterios formales y funcionales de los locales.

Este concepto va de la mano con la participación comunitaria en el proceso de realizar la propuesta de diseño. Durante una entrevista, con el Dr. John KC LIU, director del Centro de Investigación Building and Planning Foundation National University of Taiwan de la Universidad Nacional de Taiwán, afirmó que "cuando la gente participa, mantiene una conexión con el proyecto" (LIU, 2015). Es necesario involucrar a los diferentes actores en el diseño, principalmente a la comunidad. Son necesarios los procesos participativos durante la elaboración del diseño, planificación y construcción. En este artículo se detalla los procesos participativos en la etapa preliminar.

Durante el estudio de la vivienda tsáchila para determinar los criterios y poder realizar el diseño, se organizaron talleres con niños y jóvenes. Sanoff considera esencial la participación de los jóvenes para contribuir a la comunidad (Sanoff, 2000). Para este trabajo, los estudiantes del colegio Abraham Calazacón compartieron ideas para sus viviendas, además mencionaron las problemáticas más comunes dentro y fuera de su vivienda. Adicional a lo anterior, se organizó un fórum público involucrando diferentes actores de siete comunidades para la calificación del anteproyecto. Actualmente, se sigue realizando cambios en la vivienda

Figura 1. Ubicación de Santo Domingo de los Tsáchilas. Las siguientes coordenadas: $0^{\circ} 06^{\prime} \mathrm{S}-79^{\circ} 23^{\prime} 30^{\prime \prime} \mathrm{W} ; 0^{\circ} 06^{\prime} \mathrm{S}-79^{\circ} 09^{\prime} 00 \mathrm{~W}$; $0^{\circ} 25^{\prime} \mathrm{S}-79^{\circ} 23^{\prime} 30^{\prime \prime} \mathrm{W}$ y $0025^{\prime} \mathrm{S}-79^{\circ} 09^{\prime} 00^{\prime \prime} \mathrm{W} 2$ Fuente: Sistema Nacional de Información (2017). Fuente: Elaboración de Sol Intriago.
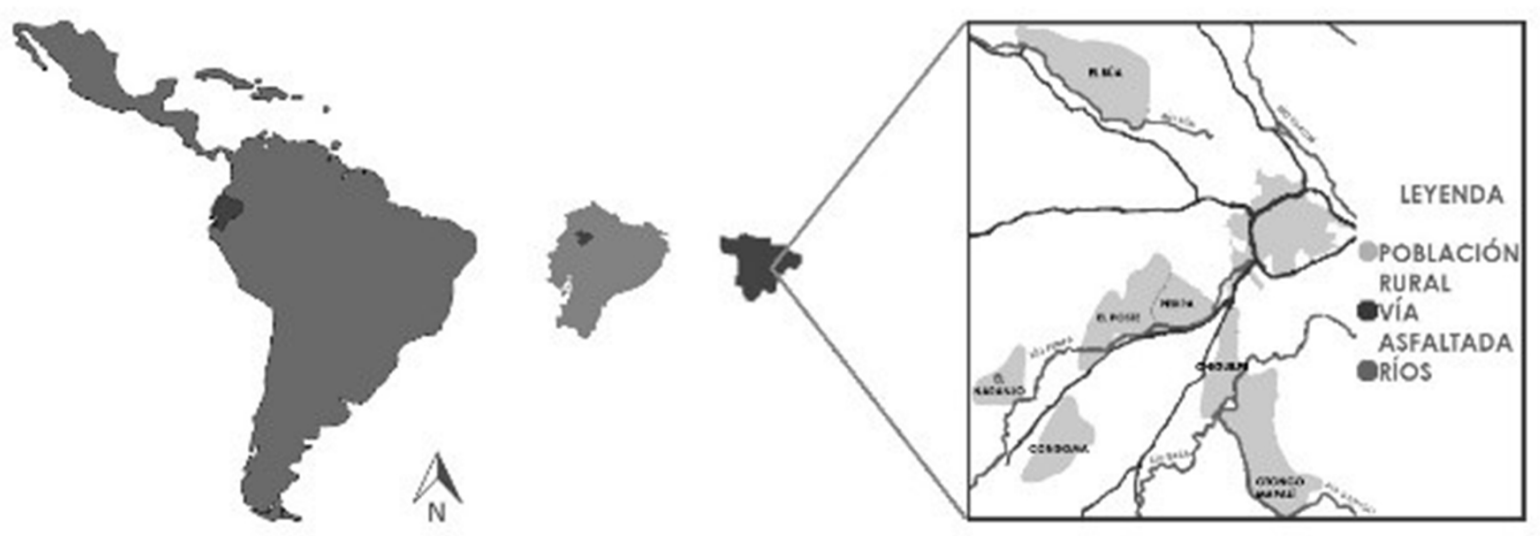

Los territorios de la nacionalidad Tsáchila están ubicados en zona rural (Fig.1). La palabra "Tsa" significa verdad y "chila" significa gente, traducido al castellano significa "verdadera gente" en su idioma llamado Tsa'fiki. Es una población de 2.319 personas, quienes están localizados en la provincia de Santo Domingo de los Tsáchilas, ubicado en la zona 4 (INEC, 2010; SENPLADES, 2013-2017), con una superficie 3.857 km². Dicha provincia tiene una población de 270.875 habitantes. La provincia consta de dos cantones: Santo Domingo con siete parroquias urbanas y siete rurales, y la Concordia con una parroquia urbana y tres rurales (Gobernación Tsáchila, 2018).

La nacionalidad Tsáchila está compuesta por siete comunas: Chiguilpe, Colorados del Búa, Cóngoma grande, Los naranjos, El poste, Peripa, Otongo Mapalí. Antes del 2002 los Tsáchilas tenían 19.119 hectáreas, pero por la invasión progresiva de colonos se han reducido a 10.050 hectáreas. Actualmente cuentan con las escrituras públicas legalmente notariadas (Consejo de Gobierno Tsáchila, 2002-2012). 
Figura 2 y 3 . Beneficios e importancia del achote en la cultura tsáchila y colocación del achote en el cabello como parte de la identidad de Los Colorados. (2017)

Fuente: Propia

El Acuerdo Ministerial № 2207 del 24 de noviembre de 1975 aprobó tanto la Gobernación Tsáchila como el "Estatuto de la Tribu de los Indios Colorados". Las comunidades están conformadas por un presidente, vicepresidente, secretario, tesorero, síndico, y un representante ante el Consejo de Gobierno Tsáchila llamado teniente (Calazacón F., comunicación personal, octubre 27, 2017). En la actualidad los presidentes de los cabildos comunales y el teniente forman el Consejo de Gobierno. La máxima autoridad recae en el gobernador (Consejo de Gobierno Tsáchila, 2002-2012).

En cuanto a la estructura poblacional según la edad, el $41 \%$ son menores de edad, llegando hasta un 55\% de personas menores de 25 años (Consejo de Gobierno Tsáchila, 2002-2012). Considerando que es una población joven y que serán futuros propietarios de nuevas viviendas es esencial trabajar en programas de capacitación para estas futuras generaciones ya que son los nuevos líderes de las comunidades.

Actualmente los Tsáchilas están integrados a la economía de mercado mediante la comercialización de plátano, cacao, café, el turismo y la medicina tradicional (Gobernación de la Nacionalidad Tsáchila Plan de Vida, 2017).

El presidente de la comunidad El Postes, Flavio Calazacón, mencionó que la mayoría de las comunidades es agrícola, una minoría se dedica a la medicina ancestral, ecoturismo y turismo de salud (Calazacón F., comunicación personal, octubre 27, 2017).

Los Tsáchilas que se dedican a la medicina ancestral son un total de sesenta chamanes, de los cuales diez son de la tercera edad, considerados sabios en el tema. Su conocimiento empírico de biología los ha llevado a ser conocidos incluso de manera internacional. Los tsáchilas son conocidos por su coloración de cabello con el uso del achote o nombre científico Bixa Orellana, que representa vida, lo utilizan como medicina para protección de la viruela, sarampión, dolores de cabeza. (Calazacón F. comunicación personal,octubre 27, 2017).

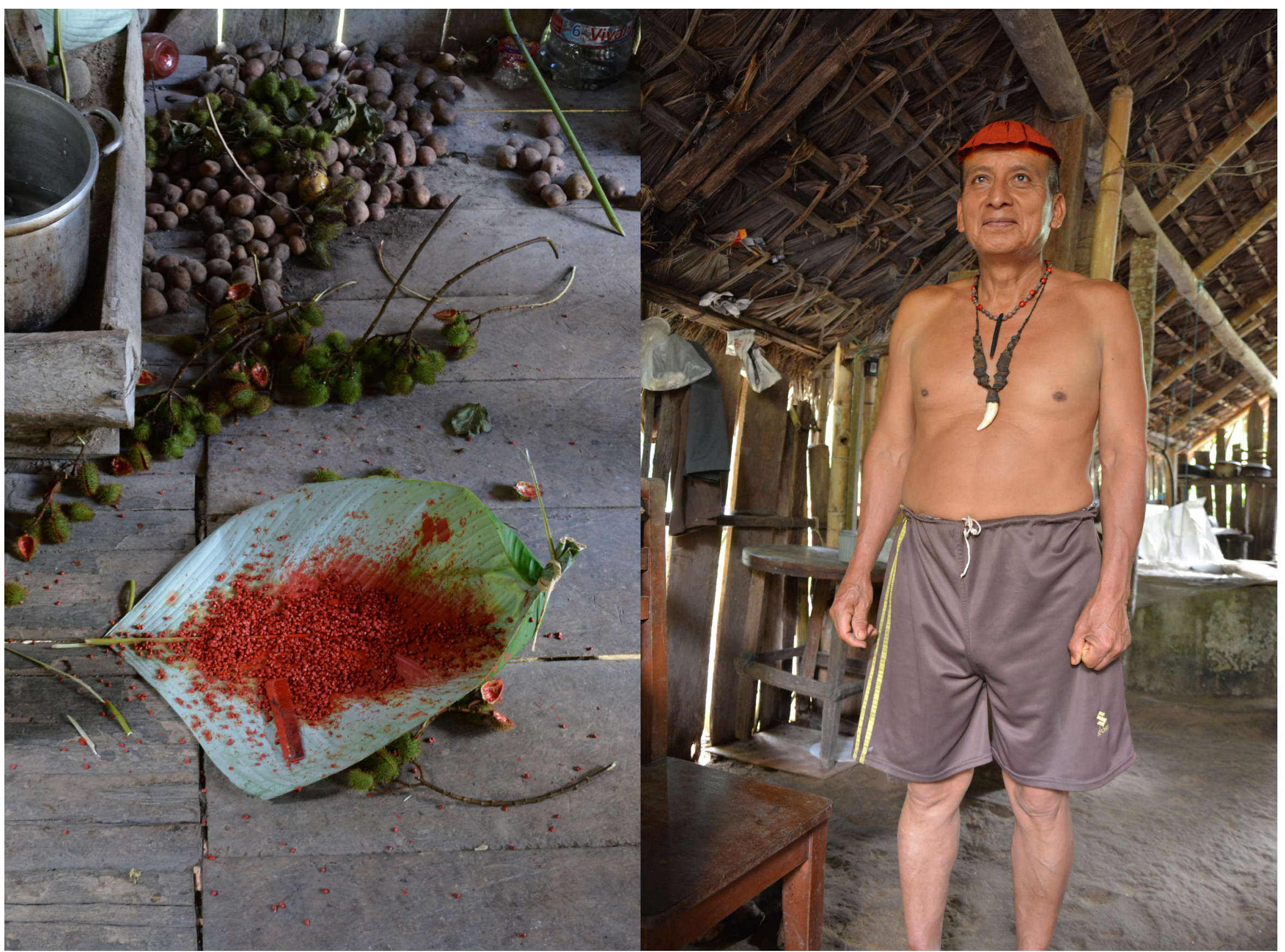




\section{Programas de vivienda de MIDUVI}

Los programas de vivienda de MIDUVI se basan en el artículo 85 de la Ley OrgánicaTerritorial, Uso y Gestión de Suelo, la cual prescribe:

La vivienda de interés social es la vivienda adecuada y digna destinada a los grupos de atención prioritaria y a la población en situación de pobreza o vulnerabilidad, en espacial la que pertenece a los pueblos indígenas, afroecuatorianos y montubios. Tanto la definición de la población beneficiara de vivienda de interés social, así como los parámetros y procedimientos que regulen su acceso, financiamiento y construcción serán determinados con base a lo establecido por el órgano recto nacional en materia de hábitat y vivienda en coordinación con el ente rector de inclusión económica y social. (Ley Orgánica de Ordenamiento Territorial, Uso y Gestión de Suelo, 2016)

El Ministerio de Desarrollo Urbano y Vivienda (MIDUVI) tiene diferentes programas de vivienda. Se trata de viviendas para aquellos que viven en pobreza extrema 0 pobreza moderada. Cuenta con el programa vivienda Copago en donde se paga en un lapso de 20 años. En el programa Casa Para Todos se encuentra dentro del marco del Plan Toda una Vida, implementado por el Gobierno Nacional, en el cual define los siguientes beneficios: una vivienda nueva en terreno urbanizado dentro del programa Casa Para Todos y la construcción de vivienda nueva en terreno propio. En el caso de las comunidades Tsáchilas, estas poseen su propio terreno (Ministerio de Desarrollo Urbano y Vivienda, 2018).

\begin{tabular}{|c|c|c|c|c|c|c|}
\hline \multicolumn{7}{|c|}{ 2. Construcción de vivienda nueva en terreno propio } \\
\hline Modalidades & $\begin{array}{c}\text { Valor } \\
\text { Incentivo de } \\
\text { vivienda USD }\end{array}$ & $\begin{array}{c}\text { Valor } \\
\text { estimado } \\
\text { de copago } \\
\text { recuperado } \\
\text { en } 20 \text { años }\end{array}$ & $\begin{array}{l}\text { Costo de la } \\
\text { vivienda }\end{array}$ & $\begin{array}{c}\text { Incentivos de } \\
\text { mejoramiento } \\
\text { de suelo \& } \\
\text { biodigestores }\end{array}$ & $\begin{array}{c}\text { Otros } \\
\text { incentivos } \\
\text { para costos } \\
\text { y gastos } \\
\text { adicionales }\end{array}$ & $\begin{array}{l}\text { Valor total de } \\
\text { la vivienda }\end{array}$ \\
\hline $\begin{array}{l}\text { Subvencionada } \\
\text { al } 100 \%\end{array}$ & $\begin{array}{c}\text { Hasta } \\
\$ 12.500+\text { IVA } \\
\text { del costo de } \\
\text { la vivienda }\end{array}$ & $\mathrm{N} / \mathrm{A}$ & $\begin{array}{c}\text { Hasta } \\
\$ 12.500+\text { IVA }\end{array}$ & $\begin{array}{c}\text { Hasta } \\
\$ 2.000+\text { IVA }\end{array}$ & $\begin{array}{c}\text { Hasta } \\
\$ 3.000+\text { IVA }\end{array}$ & $\begin{array}{c}\text { Hasta } \\
\$ 17.000+\text { IVA }\end{array}$ \\
\hline Copago 20 & $\begin{array}{c}\text { Hasta } \\
\$ 11.880+I V A \\
\text { del costo de } \\
\text { la vivienda }\end{array}$ & $\$ 1870$ & $\begin{array}{c}\text { Hasta } \\
\$ 13.750+\text { IVA }\end{array}$ & $\begin{array}{c}\text { Hasta } \\
\$ 2.000+\text { IVA }\end{array}$ & $\begin{array}{c}\text { Hasta } \\
\$ 3.000+\text { IVA }\end{array}$ & $\begin{array}{c}\text { Hasta } \\
\$ 18.750+\text { IVA }\end{array}$ \\
\hline Copago 40 & $\begin{array}{c}\text { Hasta } \\
\$ 11.260+\text { IVA } \\
\text { del costo de } \\
\text { la vivienda }\end{array}$ & $\$ 3.740$ & $\$ 15.000+$ IVA & $\begin{array}{c}\text { Hasta } \\
\$ 2.000+\text { IVA }\end{array}$ & $\begin{array}{c}\text { Hasta } \\
\$ 3.000+\text { IVA }\end{array}$ & $\begin{array}{c}\text { Hasta } \\
\$ 20.000+\text { IVA }\end{array}$ \\
\hline Copago 60 & $\begin{array}{c}\text { Hasta } \\
\$ 10.640+\text { IVA } \\
\text { del costo de } \\
\text { la vivienda. }\end{array}$ & $\$ 5.410$ & $\$ 16.250+$ IVA & $\begin{array}{c}\text { Hasta } \\
\$ 2.000+\text { IVA }\end{array}$ & $\begin{array}{c}\text { Hasta } \\
\$ 3.000+\text { IVA }\end{array}$ & $\begin{array}{c}\text { Hasta } \\
\$ 21.250+\text { IVA }\end{array}$ \\
\hline
\end{tabular}

Tabla 1. Programa de vivienda de MIDUVI con terreno propio, seg.

Figura 4. Viviendas realizadas por MIDUVI en comunidades Tsáchilas (2017).

Fuente: Propia
La vivienda actual que ofrece el MIDUVI carece de características locales debido a influencias externas. Por lo general estas viviendas son de bloques de hormigón. Por ejemplo, en la Figura 4, se puede apreciar una vivienda de una familia en la comunidad El Poste, que fue afectada por el terremoto del 16 de abril 2016. Las entidades gubernamentales buscan otras alternativas de vivienda para las comunidades autóctonas.

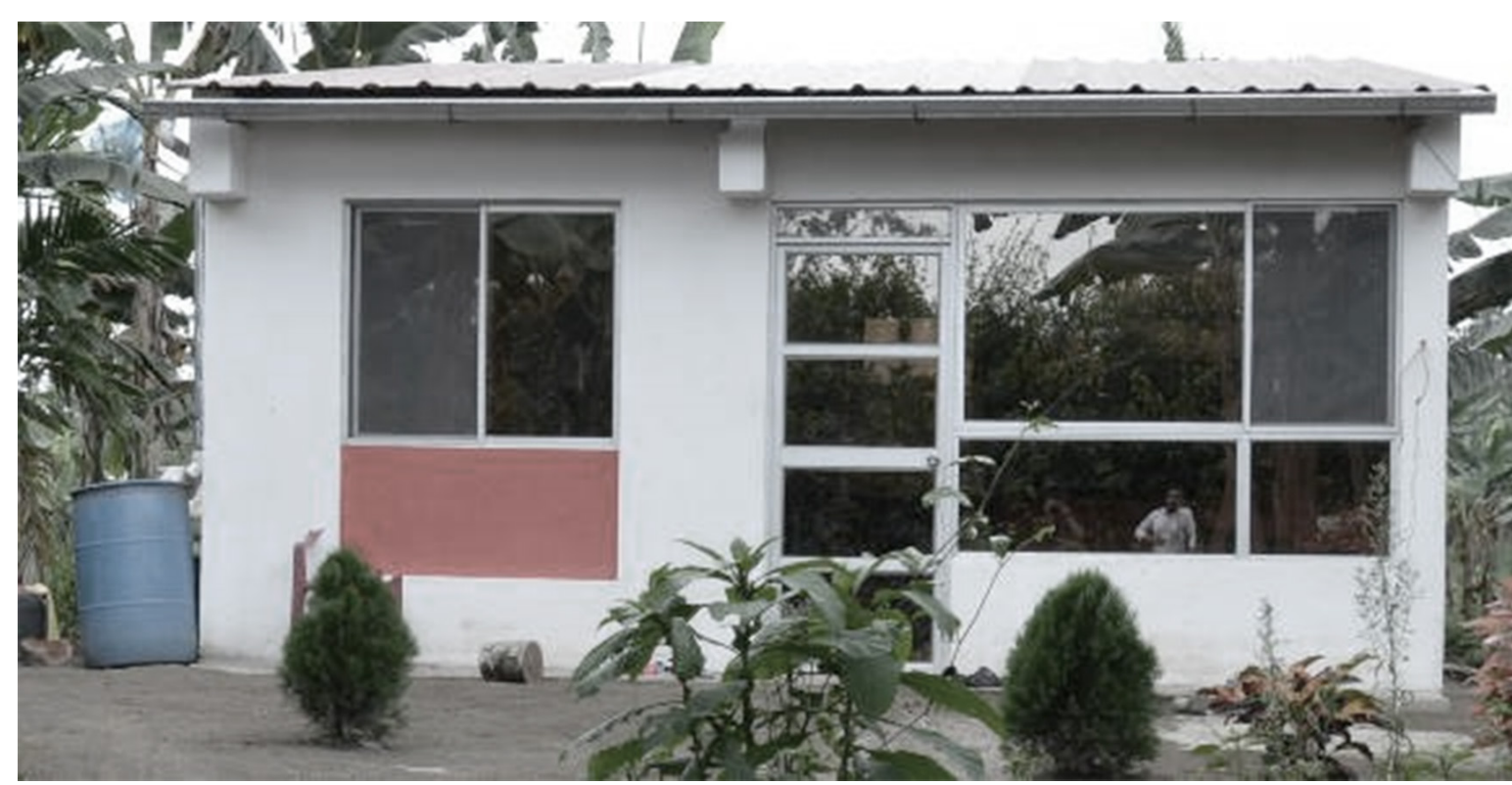




\section{Problemas de la vivienda tsáchila}

Durante el proceso de investigación se procedió a visitar tres comunidades: El Poste (1.284 ha), El Bua (2.885,60 ha) y Chiguilpe (1.138.40 ha). Las tres son parte de las siete comunidades Tsáchilas mencionadas anteriormente y ubicadas en las zonas rurales de Santo Domingo. En el Plan de Desarrollo Participativo 2002-2012, se identifica la necesidad de un programa de vivienda social tsáchila, con materiales de la zona debido al déficit cualitativo y cuantitativo de vivienda que tiene la provincia de Santo Domingo de los Tsáchilas.

Actualmente en las comunidades tsáchilas las viviendas en su mayoría son de concreto y zinc con adiciones de materiales de la zona. Por ejemplo, el $73 \%$ de las viviendas cuentan con paredes de cemento enlucido y el $88 \%$ con techo de zinc; el uso de madera para paredes es significativo en El Poste (49\%) y Naranjos (22\%) mientras que el uso de Cade o Toquilla, considerado un material característico de la vivienda vernácula, es significativo únicamente en la comuna El Poste (16\%) (Gobernación de la Nacionalidad Tsáchila Plan de Vida, 2017).

Además, las viviendas en comunidades Tsáchilas poseen solo el $9.09 \%$ de agua potable, un $65.64 \%$ posee agua de pozo, un $12.94 \%$ utiliza el río que actualmente se encuentra contaminado. Por otra parte, un $61 \%$ de los hogares dispone de pozos sépticos y $10 \%$ de letrinas. Prevalece, sin embargo, casi un 30\% de hogares que no dispone de tratamiento alguno. Ninguna de las siete comunidades Tsáchila posee sistema de alcantarillado (Gobernación de la Nacionalidad Tsáchila Plan de Vida, 2017).

En las tres comunidades que se visitó, la mayoría carecía de pozos sépticos y todo lo descargaban en el río. Esto produce problemáticas de estancamiento de agua, malos olores, enfermedades y contaminación del río. Esta contaminación ha afectado a la unidad familiar y a su cultura en general, ya que distintas actividades se generaban entorno a las orillas del río. Por ejemplo, la pesca no solo era una actividad de trabajo, también funciona para encontrar pareja ya que el mejor pescador era quien más se destacaba en la comunidad. Además, organizaban rituales alrededor del río para fomentar la unidad comunitaria (Calazacón F. , comunicación personal,octubre 27, 2017).

En cuanto al consumo de agua, esta proviene de vertientes cercanas a la comunidad o pozos construidos en cada vivienda. Sin embargo, aún existe una necesidad por agua. Además, el desalojo de aguas servidas y excretas afecta a la salud de los pobladores. Se pueden mejorar los niveles de salubridad como poner en funcionamiento el tanque elevado y colocar una manguera para el agua. También podría incorporarse sistemas de recolección del agua de lluvia para que pase por un proceso de filtración. Asimismo, la construcción de letrinas y pozos sépticos es prioridad en estos sectores.

Figura 5 y 6 . Vivienda tsáchila, adiciones en cocina de leña y área social, en comunidad Bua (2017). Fuente: Propia

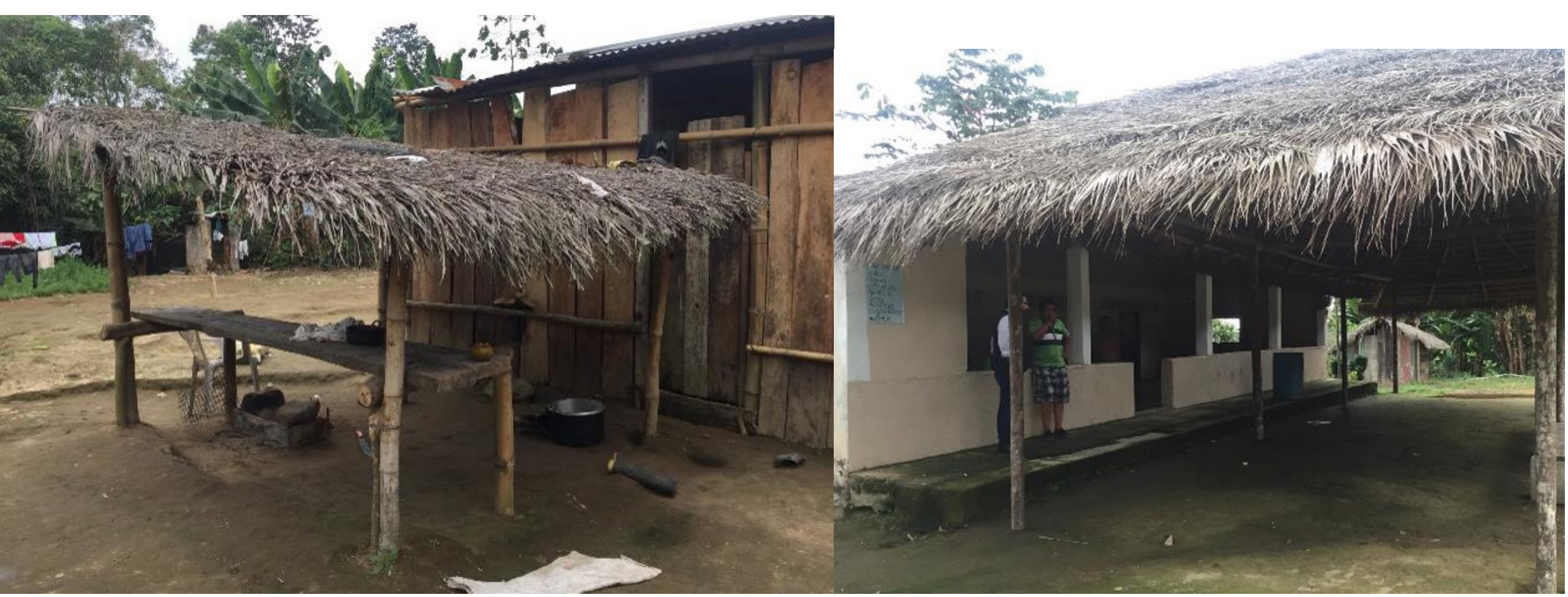




\section{Características de la vivienda vernácula Tsáchila}

La vivienda vernácula tsáchila se caracteriza por estar cerca de un cuerpo de agua, tener una sola planta y estar dividida en un área cerrada y una abierta. La zona de descanso y recreación tiene una cubierta realizada por materiales de la zona. Los materiales de la vivienda tsáchila son: chanul, el pambil, la bisola y caña guadua; la paja toquilla para la cubierta, hojas de pambil (Shi'pompo) y hojas de tawa (Tirija) (Gobernación de la Nacionalidad Tsáchila Plan de Vida, 2017). En la actualidad las viviendas son mixtas, hechas de concreto y madera con caña y con espacios de dormitorio, comedor y cocina, con extensiones de madera y caña guadua para las áreas sociales, de herramientas y la cocina de leña.

El área de trabajo y herramientas son dispersas y la zona de dormitorios suele estar en un solo sitio unificado con un vestíbulo. El área social y de comedor-cocina las adicionan a las construcciones de concreto. Las adiciones son una característica de la vivienda, ya que permite el crecimiento de las funciones de acuerdo con el uso del propietario, a esto se lo denomina vivienda incremental, es decir, la vivienda crece. Este es el concepto que se va a considerar en la propuesta arquitectónica (Ver fig. 5y 6).

Por lo general la ubicación de la vivienda es en una loma. Las fincas representan su sustentabilidad, pues es el lugar donde se vive y se trabaja con aproximadamente 10 a 40 hectáreas por familia (Calazacón F., comunicación personal, octubre 27, 2017). Algunas de las viviendas vernáculas tienen el piso directamente tocando la tierra, ya que el vínculo de estos pueblos con la misma es de suma importancia. Es por esto
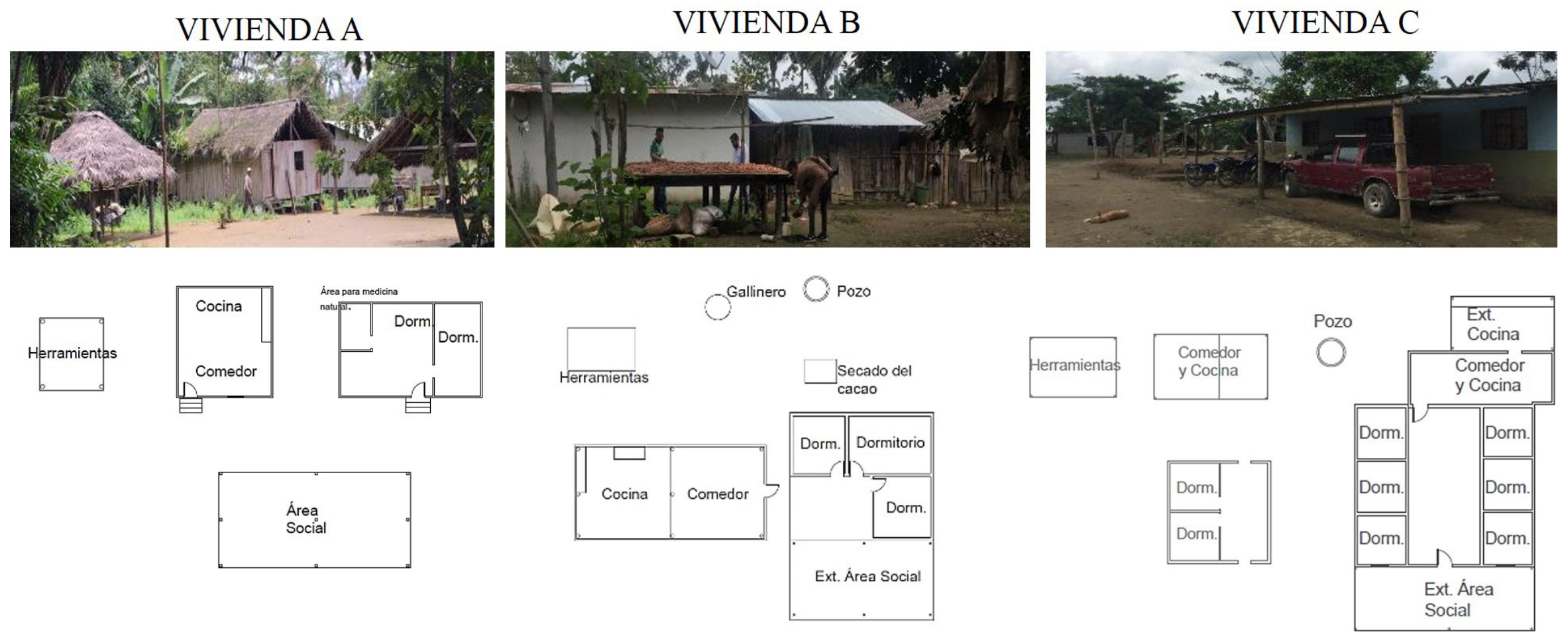

Figura 7.Viviendas en comunidades tsáchilas (2017).

Fuente: Propia que se requiere analizar en la propuesta lo anterior para considerar alternativas que mantengan sus creencias, pero a su vez brinden salubridad.

Por ejemplo, la vivienda de Flavio Calazacón (Fig.7, vivienda A) es de distribución dispersa con espacios para rituales y curaciones con dos dormitorios con estructura de madera, correas de caña guadua y cubierta hecha con paja toquilla. Su vivienda cuenta con un área para la cocina y comedor cerrado, área social abierta con cubierta de paja toquilla y área de taller también abierta con cubierta de paja toquilla. Al ingreso de la finca hay un sendero que llega hacia una loma donde se imparten talleres a visitantes y se enseña sobre los beneficios de la medicina natural. Uno de los espacios más relevantes en la cocina de los Tsáchilas es donde ubican el achote (Calazacón F., comunicación personal, octubre 27, 2017).

Héctor Aguavil (Fig.7, vivienda B), prefiere las cubiertas de paja toquilla porque son frescas en comparación al zinc. Su vivienda consta de un área social con materiales de la zona de 45 metros cuadrados y tres habitaciones conectadas con un área común de concreto en donde habitan cinco personas siendo áreas contiguas. La cocina y comedor están hechos de materiales de la zona y cuentan 70 metros cuadrados en donde la cocina es abierta y tienen espacio para moler el achote y el verde. Además, su 
vivienda tiene el pozo de agua, un lugar de secado del cacao, un área para almacenar las herramientas y el gallinero (Aguavil H., comunicación personal, octubre 27, 2017). La vivienda de Samuel Calazacón (Fig.7, vivienda C) se compone de seis dormitorios de concreto y zinc conectados con la sala, comedor y cocina en la parte posterior. En la parte delantera tiene el área social construida con materiales de la zona. Asimismo, existe una extensión de la cocina de leña hecha con materiales de la zona. Tiene un pozo de agua, un lugar para ubicar herramientas y un gallinero en la parte posterior. (Calazacón S., comunicación personal, octubre 27, 2017).

\section{Resultados de talleres sobre vivienda}

Para realización del estudio, se consideraron cuatro talleres: Vivienda y sus espacios, Problemáticas de la vivienda, Conociendo la paja toquilla y Alternativas en configuraciones de espacios. En los tres primeros talleres realizados en la comunidad El Bua, en San Jacinto del Bua Valle Hermoso y con la participación del colegio Abraham Calazacón, se dieron a conocer las características generales de la vivienda. El último taller mencionado se realizó durante un forum público titulado "Diálogo sobre la nueva Agenda Urbano Nacional-Socialización prototipo de vivienda Tsáchila", en donde participaron líderes y representantes de las siete comunidades. Durante el encuentro se realizó una votación para la propuesta del anteproyecto.

En el primer taller, "Vivienda y sus espacios", participaron 24 estudiantes quienes trabajaron en grupos de tres. Este taller tuvo como fin conocer aspectos generales de la vivienda. El 90\% de los participantes graficaban como características generales: pozos de agua, vivienda sobre loma, áreas de cultivos, gallinero, áreas de trabajo y árboles. Un 40\% dibujó dos cocinas, una en el interior de la vivienda y otra cocina de leña en la parte posterior. Finalmente, el $90 \%$ de los participantes dibujó portales de su vivienda y adiciones al exterior hechas de caña y madera. Además, el $80 \%$ de los participantes respondió que añoraba más dormitorios, ya que en sus viviendas hay un problema hacinamiento. Esta información fue corroborada durante las visitas a sitio. Los participantes preferían un dormitorio individual, en donde extendían las cubiertas para que circulara el viento. Los estudiantes que tenían piso de tierra o asfalto deseaban que sus viviendas estuviesen un poco más elevadas para evitar la entrada de insectos.

En el segundo taller, "Problemáticas de la vivienda", participaron seis grupos integrados por tres o cuatro estudiantes de 15 años. El propósito de este taller era conocer, desde el punto de vista de los adolescentes, la problemática de la vivienda y sus alrededores. Un $67 \%$ de los participantes mencionó que una de las problemáticas era el deterioro de la vivienda, que se da por varios motivos. El más mencionado fue la afectación del

Figura 8 y 9.Taller cubierta de paja toquilla de la unidad educativa Abraham Calazacón. (2017). Fuente: Propia terremoto del 16 abril 2016. Otros mencionaron la falta de agua potable, alcantarillado, organización para desechar la basura, hacinamiento, calles sin asfaltar, insalubridad en las viviendas, el material zinc que genera ruido, contaminación en los cuerpos de agua,

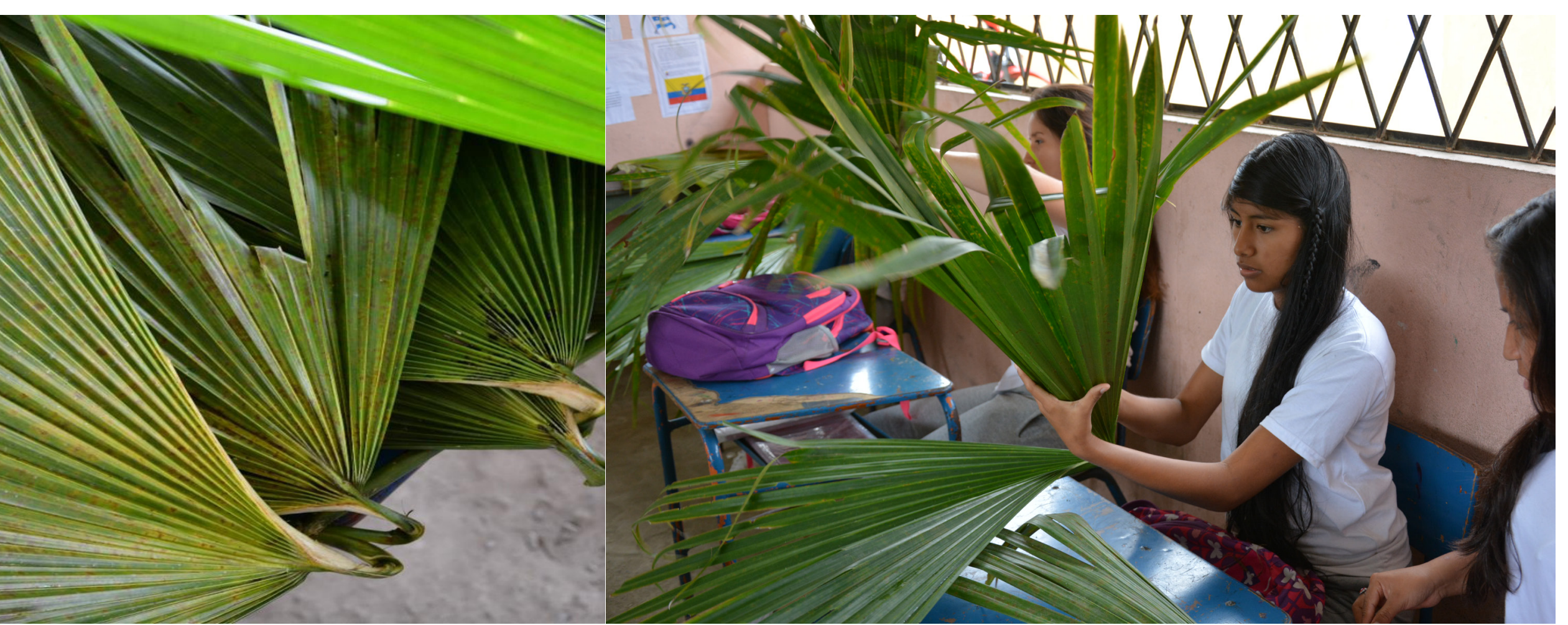


falta de señal de internet y estancamiento de agua, que se corrobora con el estudio previo de la Gobernación de la Nacionalidad Tsáchila Plan de Vida, 2017.

El taller "Conociendo la paja toquilla" consistió en una demostración sobre cómo armar la cubierta con la paja toquilla (Ver fig.8, 9). Participaron 25 estudiantes y un profesor. Este taller se basó en el conocimiento de los Tsáchilas para armar una cubierta. Se consiguieron las hojas de paja toquilla gracias a la colaboración de integrantes de la comunidad. Cada estudiante tomó una o dos hojas para la prueba de aprendizaje. El maestro enseñó el proceso de dividir la paja toquilla sin partirla completamente en dos, y luego el giro, donde se coloca una parte de la hoja sobre la otra, con un tallo doblado de 30 centímetros. Luego se ubica en las correas de la cubierta las hojas de paja, con una separación de 10 centímetros hasta cubrirla completamente. El taller es una oportunidad para aprender la técnica de la cubierta de paja toquilla tanto para los investigadores como para los adolescentes de la comunidad que desconocían dicha técnica.

En el cuarto taller, "Alternativas en configuraciones de espacios", los participantes realizaron la configuración de espacios de la vivienda, indicando sus actividades y como se conectan unas a otras. Este taller fue realizado durante el fórum público "Diálogo sobre la nueva Agenda Urbano Nacional-Socialización prototipo de vivienda Tsáchila,

\section{rî̀ \\ s⿱亠幺⿴囗十}

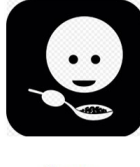

Reunirse con familiares y amigos
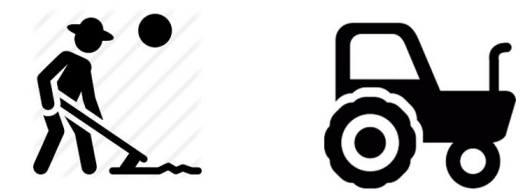

Realizar actividades

agrícolas

Figura 10 y 11. Íconos de actividades para elaborar taller (2017).

Fuente: Propia
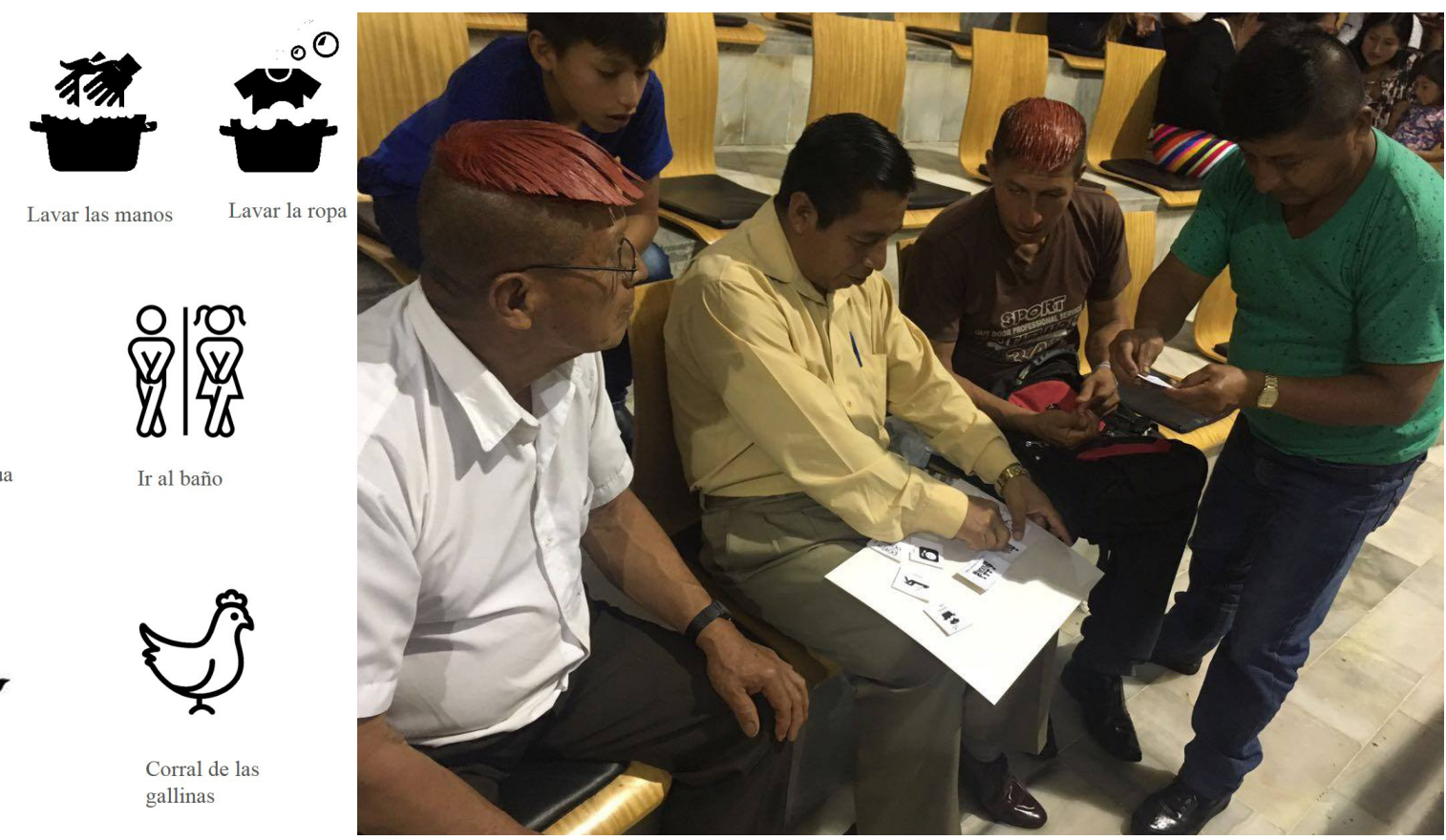

donde participaron líderes y representantes de las siete comunidades" el día 27 de octubre del 2017.

En esta fase participaron doce grupos integrados de cuatro a cinco personas. A pesar de que se realizó levantamiento de viviendas y entrevistas, el taller es una oportunidad para conocer como los pobladores conectan los espacios. Los resultados fueron similares en los doce grupos:

1. El pozo de agua está conectado a las actividades de lavado.

2. El baño está ubicado a una distancia del pozo de agua.

3. El área social es principal en la vivienda.

4. Las áreas de trabajo son el secado de cacao, siembra, herramientas, gallinero. Todos están conectados.

5. El lugar en donde está el achote y plantas medicinales es un área de estudio para los Tsáchilas.

6. El área para dormir está desconectada de las diferentes actividades.

\section{Calificación de propuesta de vivienda tsáchila.}

En el proceso de socialización del anteproyecto (Fig.12) se consideró la opinión de la mayoría de los integrantes de la comunidad Tsáchila. En este proceso se tuvo la participación de treinta y siete personas que calificaron la propuesta de este anteproyecto. Durante la selección se dio tres alternativas "me gusta", "más o menos", "no me gusta". 
Figura 12. Durante la calificación de propuesta ante-proyecto, que continua en proceso de socialización (2017)

Fuente: Propia

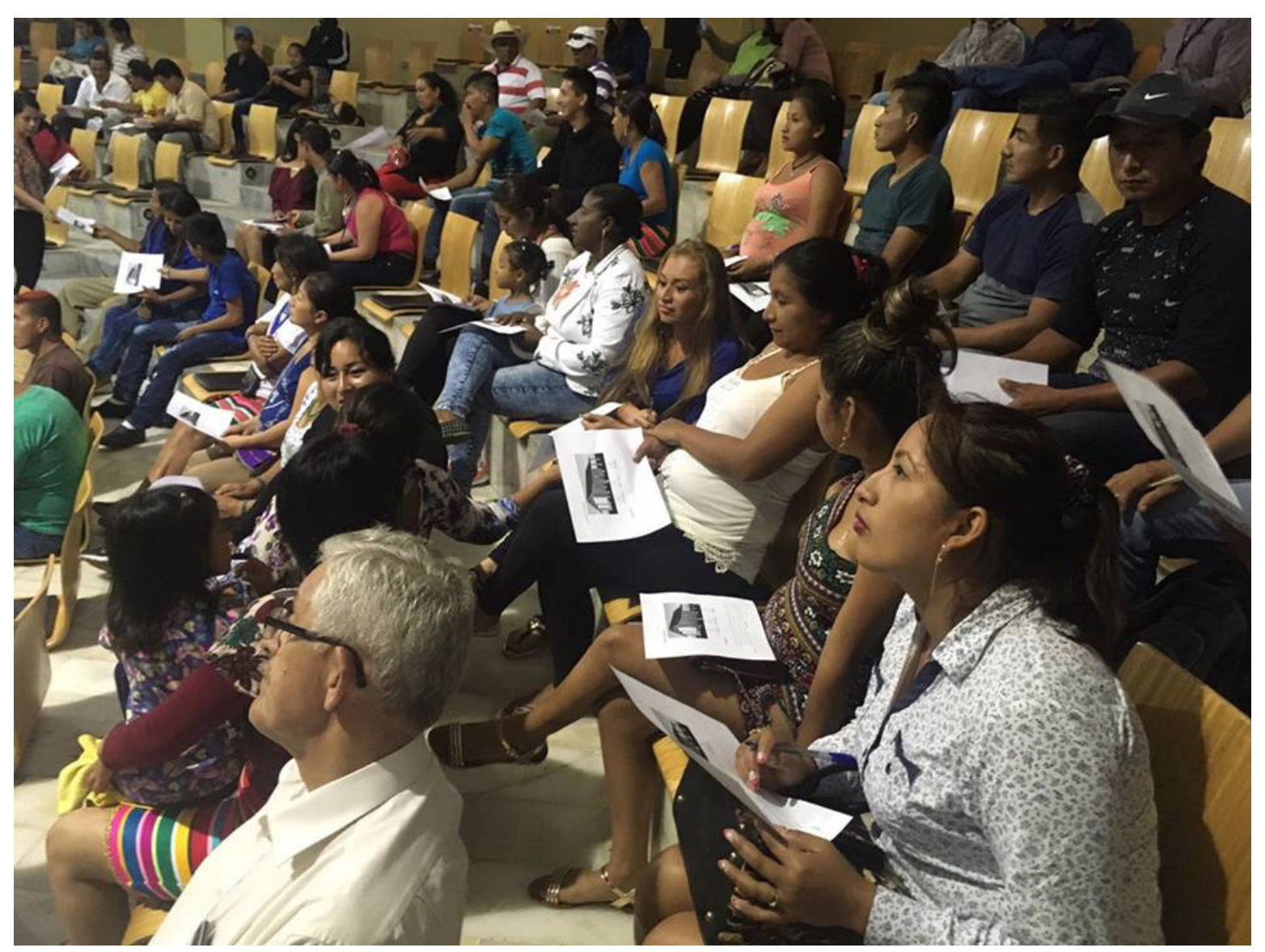

En total se obtuvo un $70 \%$ de aceptación del anteproyecto. El proceso de socialización aún continúa, ya que hubo dudas en cuanto al material de caña.

\section{Recomendaciones}

Después de la visita de campo de los investigadores y, con base en los talleres, la observación, las entrevistas así y el levantamiento de vivienda, se sugiere la propuesta de anteproyecto que se visualiza en la Figura 13.
Figura 13. Anteproyecto de vivienda Tsáchila (2017).

Fuente: Diseñada por Arq. Diego Ponce, Arq

Daniela Hidalgo

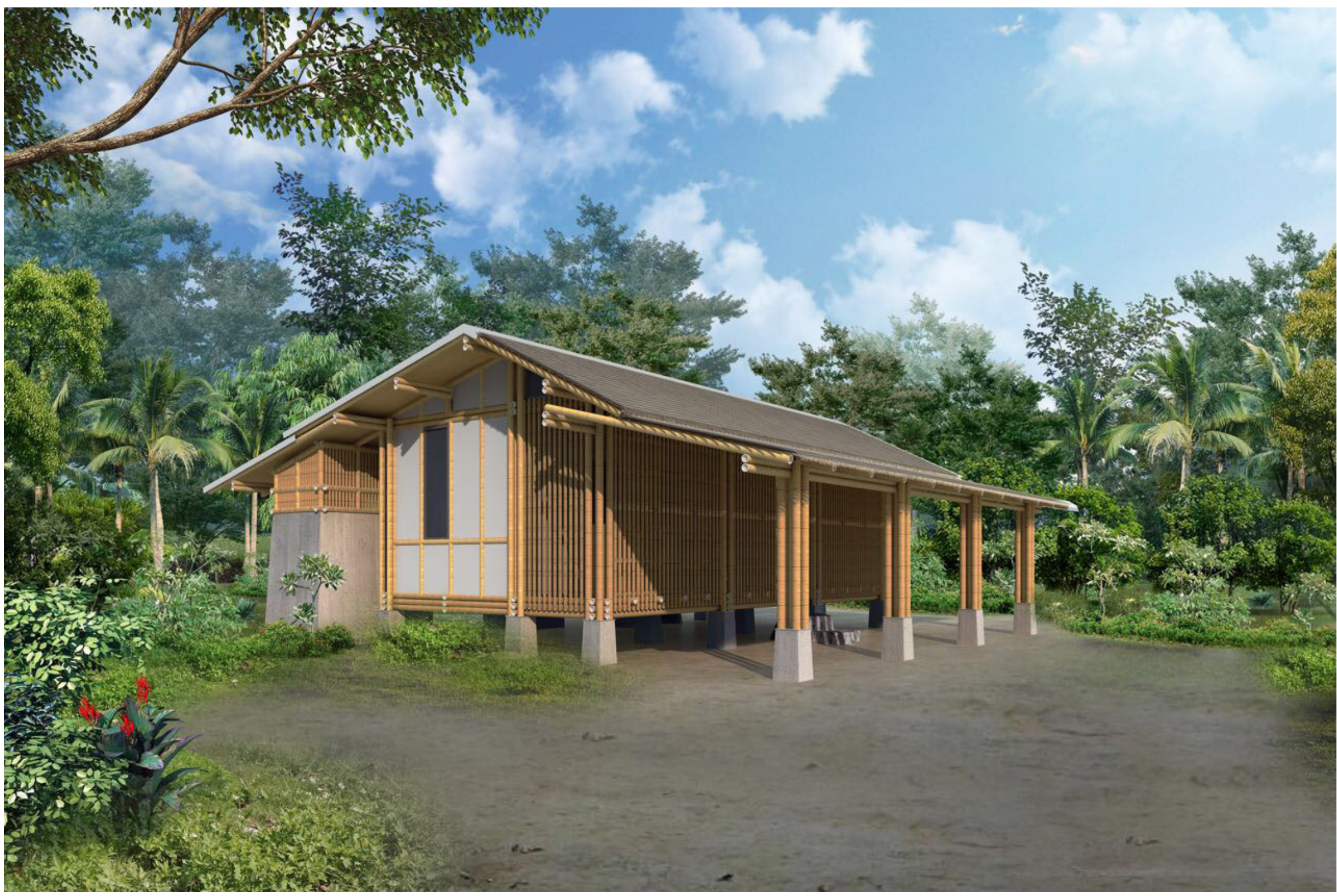



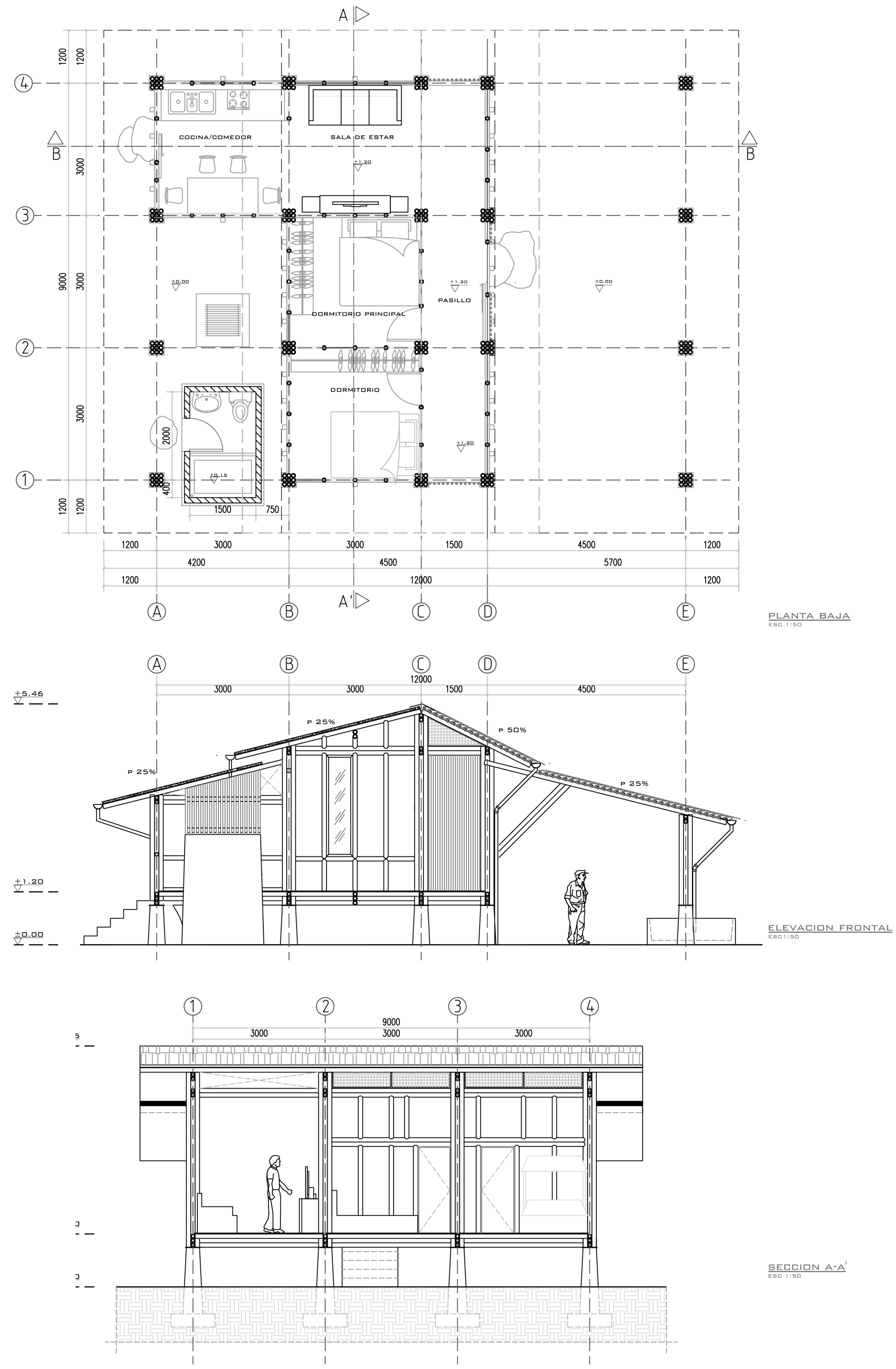
Arquitectónicamente se propone un espacio de $50 \mathrm{~m} 2$ que incluye dos dormitorios y cocina conectados por un pasillo amplio junto con un baño externo y una proyección de columnas para el crecimiento de la vivienda, fomentando así las áreas sociales y la cocina a leño, ya que son características de la vivienda tsáchila.

Respecto a los materiales a utilizarse se propone el uso de la caña guadua como material predominante estructural. El hormigón armado puede ser empleado en las bases. En la propuesta, parte de la cubierta se recomienda hacerla con paja toquilla tanto en áreas sociales, como en la fachada frontal. En la fachada posterior se plantea el uso de plancha metálica de zinc o aluminio corrugados, esto por su fácil instalación, sobre 5 centímetros de cemento espumoso ligero para reducir el ruido y aumentar el aislamiento térmico. Todo esto sobre caña picada y asentado sobre la estructura.

Juntamente con la cubierta metálica, se proyecta el sistema de recolección y filtración de aguas de lluvia para su uso diario tanto en la preparación de alimentos, como para el aseo personal. La paja toquilla es un material local que usado en la cubierta facilita la ventilación pasiva, manteniendo fresco el espacio. Sin embargo, su utilización es laboriosa y por eso nos hemos limitado a usarla en la fachada frontal como elemento visual propio de la cultura constructiva Tsáchila.

En planta, el diseño consiste en un módulo central con la posibilidad de expandirse a lo largo y ancho (Ver figura 14). El número de miembros que conforman cada familia Tsáchila es muy variado y por eso se debe dar la opción de incrementar la vivienda según se necesite. El MIDUVI presenta dos condiciones para la vivienda: la primera limitante es que el área que no puede sobrepasar de $50 \mathrm{~m} 2$ de construcción y la segunda es el presupuesto que oscila entre los $\$ 12,500$ a los $\$ 16.250$ dólares por costo de cada vivienda. Por estas razones se propone que la construcción del módulo central sea llevada por el MIDUVI y las adiciones sean realizadas autónomamente por la población Tsáchila.

En planta, el diseño consiste en un módulo central con la posibilidad de expandirse a lo largo y ancho (Ver figura 14). El número de miembros que conforman cada familia Tsáchila es muy variado y por eso se debe dar la opción de incrementar la vivienda según se necesite. EI MIDUVI presenta dos condiciones para la vivienda: la primera limitante es que el área que no puede sobrepasar de $50 \mathrm{~m} 2$ de construcción y la segunda
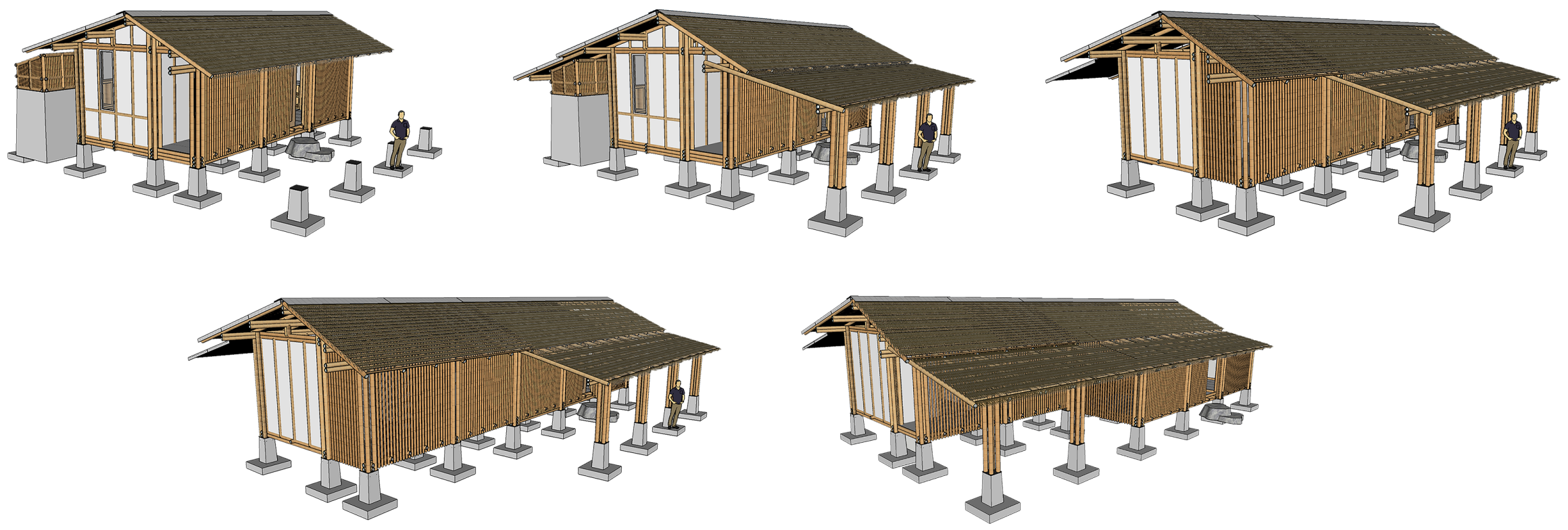

Figura 15.Anteproyecto (2017).

Fuente: Diseñada por Arq. Diego Ponce, Arq. Daniela Hidalgo es el presupuesto que oscila entre los $\$ 12,500$ a los $\$ 16.250$ dólares por costo de cada vivienda. Por estas razones se propone que la construcción del módulo central sea llevada por el MIDUVI y las adiciones sean realizadas autónomamente por la población Tsáchila.

Es necesario que en el abordaje del tema vivienda se considere brindar capacitaciones, o se den charlas a la población sobre el tratamiento del agua, mantenimiento de las letrinas, reciclaje de basura y mantenimiento de pozos sépticos, así como de higiene y salubridad de sus espacios. Para poder realizar proyectos de vivienda es indispensable trabajar en conjunto con las comunidades en procesos participativos, con el fin de que ambas partes aprendan de procesos constructivos para que las estas comunidades puedan realizar reparaciones y expansiones de forma autónoma. 
Se requiere la participación público-privado en los procesos de vivienda, pues es esencial contar con la participación de diferentes actores, como por ejemplo la comunidad Tsáchila, el Ministerio de Desarrollo Urbano y Vivienda (MIDUVI), las Organizaciones No Gubernamentales y las empresas privadas. También contar con el apoyo técnico e investigativo de las Universidades.

\section{Conclusión}

La propuesta busca alinearse al Plan de Desarrollo Participativo 2002-2012 que tiene como objetivo incentivar la construcción de la vivienda con material de la zona, la participación comunitaria, y promover la identidad arquitectónica. Para alcanzar dicho objetivo, los autores utilizaron el diseño participativo como herramienta para la realización del anteproyecto mediante talleres, en donde se identificaron criterios formales y funcionales de la vivienda tsáchila.

Con el objetivo de determinar las características de la vivienda se realizaron entrevistas, visitas a sitio, levantamiento de viviendas, talleres con jóvenes y un fórum con representantes de siete comunidades Tsáchilas para calificar el anteproyecto; cabe mencionar que continúa el proceso de participación para una propuesta final.

La vivienda tsáchila ha tenido transformaciones con el paso del tiempo pues se ha ido modificando con el uso de materiales de la zona y, actualmente, con la utilización mixta de materiales tanto de la zona o ajenos a la misma. Como una característica general, la vivienda crece en sus espacios, por ejemplo, la cocina de leño y las áreas sociales son adiciones comunes. Además, están consideradas bajo este concepto funciones dispersas de la vivienda que sirven para el trabajo agrícola como lo son el cuarto de herramientas, secado del cacao y el gallinero.

Por esta razón, la propuesta de vivienda se enfatiza en el módulo principal con la posibilidad de expansión a lo largo y ancho según las necesidades del usuario. Se sugiere que el MIDUVI pueda realizar el módulo central, mientras que las adiciones sean realizadas autónomamente por las familias y vecinos de acuerdo con sus requerimientos.

El material de caña guadua como estructura y de mayor jerarquía en la propuesta sigue en discusión, ya que los Tsáchilas lo consideran un material inseguro y no duradero, por lo que proponen utilizarlo en zonas culturales.

Frente a esta situación es imperante la necesidad de efectuar un prototipo de escala real en una de las comunidades Tsáchilas con la participación de los locales. Se sugiere que durante este proceso se realice una capacitación acerca del tratamiento y sus beneficios de la caña guadua.

La vivienda representa el vivir de los seres humanos por lo que es esencial que se estudie la forma de vida y espacios más utilizados para así buscar alternativas que se acoplen a las necesidades de los usuarios, buscando el crecimiento y adaptabilidad de esta. Estas alternativas es de vital importancia socializarlas con la comunidad y que ellos protagonicen el proceso desde la evaluación del anteproyecto, proyecto y su construcción.

\section{Agradecimientos}

Agradecemos a las diferentes comunidades tsáchilas que han participado en el estudio de la vivienda durante las entrevistas, los levantamientos y los talleres. A los líderes comunitarios que con entusiasmo nos ayudaron durante el proceso de recopilación de información para proponer el anteproyecto. Al centro de investigación de la Universidad de Especialidades Espíritu Santo (UEES) por apoyar procesos participativos en comunidades rurales. A la decana Arq. Natalie Wong por su apoyo incondicional. A Sol Intriago, estudiante de arquitectura, que durante sus prácticas pre-profesionales realizó aportes en los procesos de investigación. Al arquitecto Diego Ponce por la propuesta de diseño arquitectónico basado en los estudios previos de la vivienda. A Gisela Raymond, 
docente de la Universidad Laica, por su gran aporte al proyecto de investigación. Al arquitecto Jonathan Carpio por la iniciativa de este proyecto que vincula a la academia. A la Arq. María Luisa Ortega, por brindar su apoyo técnico e información que ayudó a generar este estudio.

\section{Referencias Bibliográficas}

Alexander, I. e. (1977). A Pattern Language. Towns. Buildings. Construction. Nueva York: Oxford Press.

Aravena, A. (2013). Elemental: Incrementral Housing and Participatory Design Manual. Ostfildern: Bilingual.

Arboleda, G. ( 2006). Qué es la Arquitectura Vernácula? Recuperado el 16 de diciembre de 2013, de http://www.arquitecturavernacula.com/web/articulos/articulo/498

Cárdenas, A. (2014). Arquitectura vernácula residencial en Lamas, Perú: un estudio tipológico. Peru: Universidad Femenina del Sagrado Corazón.

Consejo de Gobierno Tsáchila. (2002-2012). Plan de Desarrolo Participativo Siete Comunidades Tsáchilas. Santo Domingo: Consejo de Gobierno Tsáchila.

Constitución de la República del Ecuador. (20 de octubre de 2008). Asamblea Nacional. Obtenido de Constitución 2008, dejemos el pasado atrás: http://www. asambleanacional.gob.ec/sites/default/files/documents/old/constitucion_de_ bolsillo.pdf

El Ministerio de Desarrollo Urbano y Vivienda MIDUVI. (s.f.). Obtenido de Habitat y Vivienda en http://www.habitatyvivienda.gob.ec/

Gehl, J., \& Svarre, B. (2013). How to Study Public Life. Island Press.

Gobernación de la Nacionalidad Tsáchila Plan de Vida. (2017). Plan del Buen Vivir Nacionalidad Tsáchila. Santo Domingo: Gobierno de la provincia de Santo Domingo de los Tsáchilas, secretaría de los pueblos, movimientos sociales y participación ciudadana.

Gobernación Tsáchila. (2018). http://gobernacionsdtsachilas.gob.ec/la-gobernacion/.

González, H. (2007). Vivienda tradicional de la Cañada (Zopoco, Mich). Arquitectura vernácula en el mundo ibérico, 218-224.

Hester, R. (mayo del 2015). Comunicación personal. (D. Hidalgo, Entrevistador)

Hester, R. T. (1990). Community Design Primer . Ridge Times Pr.

INEC. (2018). Proyección de la población ecuatoriana, por años calendario, según cantones. Proyección de población ecuatoriana 2010-2020.

SENPLADES (2013-2017). Agenda Zonal 4. Obtenido de http://www.planificacion.gob. ec/wp-content/uploads/downloads/2015/11/Agenda-zona-4.pdf

Ley Orgánica de Ordenamiento Territorial, Uso y Gestión de Suelo. (5 de julio de 2016). Asamblea Nacional. Obtenido de Capítulo IV: Vivienda de interés social, artículo 85 de https://www.habitatyvivienda.gob.ec/wp-content/uploads/downloads/2017/05/ LOOTUGS-Registro-Oficial.pdf

LIU, J. K. (12 de Mayo de 2015). Comunicación personal. (D. Hidalgo, Entrevistador)

Ministerio de Desarrollo Urbano y Vivienda. (Diciembre de 2015). Informe Nacional del Ecuador: tercera conferencia de las Naciones Unidas sobre la vivienda y el desarrollo urbano sostenible, Habitat III. Obtenido de Subsecretaría de Hábitat y Asentamientos Humando- SHAH: http://www.habitatyvivienda.gob.ec/wp-content/ uploads/downloads/2017/05/Informe-Pais-Ecuador-Enero-2016_vf.pdf

Ministerio de Desarrollo Urbano y Vivienda. (2018). Acuerdo Ministerial 002-18. Obtenido de https://www.habitatyvivienda.gob.ec/wp-content/uploads/downloads/2018/01/ acuerdo_002-18.pdf 
Naciones Unidas. (1996). Informe de la Conferencia de las Naciones Unidas sobre los asentamientos humanos (HABITAT II). Obtenido de https://unhabitat.org/wpcontent/uploads/2014/07/12040_Habitat_II_report_Spanish.pdf

Naciones Unidas. (17 al 20 de octubre de 2016). Aplicación de los resultados de las Conferencias: Asamblea General. Obtenido de http://www.habitatyvivienda.gob. ec/wp-content/uploads/downloads/2017/05/NUEVA-AGENDA-URBANA.pdf

Ornelas, S., \& Amado, M. (2014). Incremental Housing as a Method to the Sustainable Habitat. PLEA. Obtenido de http://www.plea2014.in/wp-content/uploads/2014/12/ Paper_4B_2620_PR.pdf

Posición Nacional HABITAT III. (2016). Comité Técnico Interinstitucional para el proceso preparatorio de HABITAT III. Obtenido de http://www.habitatyvivienda.gob.ec/wpcontent/uploads/downloads/2017/05/Posicio\%CC\%81n-Nacional-HABITAT-IIIOct-2016-FN.pdf

Sanoff, H. (2000). Community Participation Methods in Design and Planning. Guayaquil: John Wiley \& Sons, Inc.

Solis, H. (2014). Análisis de la vivienda vernácula en sacapulas, una muestra gráfica representativa. Guatemala: Universidad de San Carlos de Guatemala.

Velasco, B. (31 de Julio de 2016). Santo Domingo: Un análisis a las plantas tsáchilas. El Comercio. 